Insisiva Dental Journal, Vol. 6 No. 2 Bulan November Tahun 2017

\title{
Hubungan Antara Nilai Progress Test Dengan Nilai Indeks Prestasi Kumulatif Lulusan Dokter Gigi Program Studi Pendidikan Profesi Dokter Gigi Universitas Muhammadiyah Yogyakarta
}

Correlation Between Progress Testing Score On Profession Stage With Cumulative Grade Point Academic Of Graduated Dentistry Student Of University Of Muhammadiyah Yogyakarta

\author{
Sri Utami ${ }^{1}$, Indri Kurniasih ${ }^{2}$, Arina Ismah Afiati $^{3}$ \\ ${ }^{1}$ Bagian Ilmu Kesehatan Gigi Masyarakat PSKG UMY \\ ${ }^{2}$ Bagian Medical Education PSKG UMY \\ ${ }^{3}$ Mahasiswa PSKG FKIK UMY \\ Korespondensi: utamikg@yahoo.com
}

\begin{abstract}
Background: Competence standard is a reference to implement the learning process in dentistry, one of this competence is knowledge that consist of learning method. The purpose of learning method is to train the clinical reasoning skill that measured by progress test. Progress test has a correlation between Grade Point Average (GPA) and Objective Structured Clinical Examination (OSCE).

Objective: the objective of this study was to know the correlation between the score of progress test with Cumulative Grade Point Average (CGPA) score of graduated dental students of Muhammadiyah University of Yogyakarta.

Methods: this was an observational analytics using a cross sectional design. The subjects were 112 graduated Dentistry students of Muhammadiyah University of Yogyakarta and selected using total sampling technique. The data that used in this research was progress test score and CGPA score. Data analysis used Pearson's correlation.

Result: the result showed that there was a medium correlation between progress testing score and CGPA score with a positive direction. The mean of progress test score was 45.42 and the mean of CGPA score was 3.40.

Conclusion: there is a correlation between progress test score and CGPA score in graduated Dentistry students. The highest progress test score, the highest CGPA score.
\end{abstract}

Keywords: Progress test, Cumulative Grade Point Academic (CGPA)

\footnotetext{
Abtrak

Latar Belakang: Standar kompetensi merupakan suatu acuan dalam melaksanakan proses pembelajaran pada pendidikan dokter gigi, salah satu standar kompetensi yaitu pengetahuan yang didalamnya berisi tentang metode pembelajaran. Metode pembelajaran bertujuan untuk mengasah kemampuan clinical reasoning yang diukur menggunakan progress test. Hasil nilai progress test memiliki hubungan dengan nilai Indeks Prestasi Kumulatif(IPK) dan nilai Objective Structured Clinical Examination (OSCE).

Tujuan Penelitian: tujuan dari penelitian ini adalah untuk mengetahui hubungan antara nilai progress test pendidikan profesi dengan nilai IPK lulusan dokter gigi PSPDG UMY.
} 
Sri Utami, Indri Kurniasih, Arina Ismah Afiati | Hubungan Antara Nilai Progress Test Dengan Nilai Indeks Prestasi Kumulatif Lulusan Dokter Gigi Program Studi Pendidikan Profesi Dokter Gigi Universitas Muhammadiyah Yogyakarta

Metode Penelitian: jenis penelitian ini adalah observasional analitik dengan menggunakan design cross sectional. Sampel penelitian adalah data sekunder dari 112 mahasiswa Program Studi Pendidikan Profesi Dokter Gigi UMY yang terdiri dari 3 angkatan yaitu dari angkatan 2006, 2007 dan 2008 serta dipilih menggunakan teknik total sampling. Data yang digunakan pada penelitian ini adalah nilai progress test dan nilai IPK lulusan. Analisa data yang digunakan adalah uji korelasi Pearson.

Hasil: terdapat hubungan yang sedang antara nilai progress test dengan nilai IPK lulusan dokter gigi Program Pendidikan Profesi Dokter Gigi UMY. Rata-rata nilai progress test yaitu 45.42 dan rata-rata nilai IPK yaitu 3.40.

Kesimpulan: terdapat hubungan antara nilai progress test dengan nilai IPK lulusan dokter gigi Program Pendidikan Profesi Dokter Gigi UMY, semakin besar nilai progress test, maka semakin besar pula nilai IPK lulusan dokter gigi UMY.

Kata Kunci: Progress test, Indeks Prestasi Kumulatif (IPK)

\section{PENDAHULUAN}

Pendidikan kedokteran gigi adalah pendidikan akademik profesional. Pendidikan akademik profesional tersebut mencakup pendidikan dan pelatihan untuk memperoleh ilmu pengetahuan bidang kedokteran gigi, keterampilan klinik sekaligus sikap sebagai seorang dokter gigi yang profesional. ${ }^{1}$ Dokter gigi harus bersikap profesional karena profesi dokter gigi mempunyai peranan yang besar dalam bidang kesehatan gigi dan mulut. Pendidikan profesi dokter gigi harus didasari oleh dasar keilmuan yang kokoh sehingga dokter gigi akan mempunyai kompetensi di bidang akademik serta mempunyai jiwa profesional yang diperoleh melalui pendidikan profesi yang telah didasari oleh pendidikan akademik. ${ }^{2}$

Setiap institusi pendidikan dokter gigi di beri hak otonomi akademik. Hak otonomi akademik tersebut memberi kebebasan dalam pengelolaan program studi dan pengalokasian sumber daya yang dibutuhkan untuk implementasi dari institusi tersebut. ${ }^{3}$ Program Studi Pendidikan Profesi Dokter Gigi FKIK UMY menyesuaikan kurikulum pendidikannya dengan standar kompetensi dokter gigi Indonesia dan standar pendidikan profesi dokter gigi tahun 2006. Kurikulum tersebut adalah kombinasi antara Kurikulum Berbasis Kompetensi (KBK) dengan paradigma baru dengan kurikulum lokal fakultas. ${ }^{4}$

Program Studi Pendidikan Profesi Dokter Gigi FKIK UMY menerapkan kurikulum berbasis kompetensi yang mengacu pada standar kompetensi dokter gigi Indonesia yang di dalamnya berisi pembelajaran terstruktur, sistematis dan terukur dalam pendekatan integrasi klinik yang merupakan bagian dari sistem integrasi. Integrasi klinik pada RSGM UMY (Rumah Sakit Gigi dan Mulut Universitas Muhammadiyah Yogyakarta) memadukan berbagai metode pembelajaran yaitu problem solving learning, case based learning dan community based learning. Proses pendidikan profesi dokter gigi terdiri dari beberapa kegiatan, yaitu Bed Side Teaching (BST)-Modifikasi KG, Direct Observation Prosedural Skills (DOPS), Case Report Session (CRS), Resources Person Session (RPS), case reflection, pengabdian masyarakat, progress test tahap profesi, E-case dan mentoring. Kurikulum pendidikan dokter gigi pada tahap profesi ditempuh selama 3 semester yang terbagi menjadi dua tahap yaitu tahap integrasi klinik yang terdiri dari 24 SKS 
dan tahap integrasi kesehatan masyarakat yang terdiri dari 6 SKS yang hasil dari pembelajaran tersebut mempunyai nilai akhir berupa Indeks Prestasi Kumulatif(IPK) tahap profesi. ${ }^{5}$ Indeks Prestasi Kumulatif (IPK) merupakan suatu angka yang digunakan untuk mengukur prestasi dan mengevaluasi hasil studi mahasiswa yang didapatkan dari jumlah angka mutu dibagi dengan jumlah Satuan Kredit Semester (SKS). ${ }^{6}$

Standar kompetensi dokter gigi salah satunya adalah pengetahuan. Pengetahuan tersebut dapat dicapai dengan pencapaian kemampuan mahasiswa dalam menganalisa masalah dan memecahkan masalah klinis (clinical reasoning). 7 Salah satu penilaian untuk mengetahui kemampuan clinical reasoning mahasiswa adalah menggunakan progess test yaitu merupakan kegiatan dalam pendidikan profesi yang digunakan sebagai self evaluation dalam mengetahui sejauh mana kompetensi yang sudah dikuasai oleh mahasiswa pendidikan profesi.4 Progress test adalah tes yang digunakan untuk mengukur perkembangan dari pengetahuan dan clinical reasoning. Progress test didalamnya terdiri dari soal tentang pengenalan pola diagnostik dan interpretasi data klinis. 8

Progress test memiliki hubungan nilai Objective Structured Clinical Examination (OSCE) dengan kekuatan hubungan lemah sampai sedang. ${ }^{9}$ Nilai progress test dan nilai IPK memiliki hubungan yang lemah sampai kuat pada sistem pembelajaran Problem Based Learning (PBL). ${ }^{10}$

\section{METODE}

Jenis penelitian ini adalah observasional analitik dengan desain penelitian cross sectional.
Penelitian ini di lakukan di Rumah Sakit Gigi dan Mulut Universitas Muhammadiyah Yogyakarta dan dilaksanakan pada pada bulan Februari 2016 sampai Maret 2016. Sampel pada penelitian ini adalah mahasiswa profesi Program Studi Pendidikan Profesi KG UMY angkatan 2006 sampai 2008 yang sudah mengikuti progress test tahap profesi yang berjumlah 112 mahasiswa. Teknik sampling yang digunakan pada penelitian ini menggunakan teknik non probability sampling yaitu total sampling. Kriteria inklusi pada penelitian ini yaitu mahasiswa profesi Program Studi Pendidikan Profesi KG UMY tahun 2006 sampai 2008 yang sudah mengikuti 3 kali progress test pendidikan profesi dan memiliki nilai IPK lulusan dokter gigi. Instrumen penelitian ini adalah data sekunder nilai progress test pendidikan profesi dan nilai IPK lulusan dokter gigi.

Analisis deskriptif yang digunakan dalam penelitian ini adalah analisis distribusi rata-rata yang bertujuan untuk mengetahui distribusi rata-rata nilai progress test pendidikan profesi dan nilai IPK lulusan dokter gigi berdasarkan tahun angkatan dan jenis kelamin. Analisis bivariat yang digunakan pada penelitian ini adalah uji Pearson karena distribusi data normal. Analisis ini bertujuan untuk mengetahui hubungan antara nilai progress test pendidikan profesi dengan nilai IPK lulusan dokter gigi, kekuatan hubungan, dan arah hubungan.

\section{HASIL}

Seluruh data sekunder nilai progress test pendidikan profesi dan nilai IPK lulusan dokter gigi dilakukan uji normalitas data dengan menggunakan metode KolmogorovSmirnov. Hasil uji normalitas data dengan 
Sri Utami, Indri Kurniasih, Arina Ismah Afiati | Hubungan Antara Nilai Progress Test Dengan Nilai Indeks Prestasi Kumulatif Lulusan Dokter Gigi Program Studi Pendidikan Profesi Dokter Gigi Universitas Muhammadiyah Yogyakarta

metode Kolmogorov-Smirnof dapat dilihat pada Tabel 1 berikut ini:

Tabel 1. Hasil uji normalitas data dengan menggunakan Kolmogorof-Smirnov

\begin{tabular}{lccc}
\hline & \multicolumn{3}{c}{ Kolomogorov-Smirnof } \\
\cline { 2 - 4 } & Statistik & $\mathrm{n}$ & Signifikansi \\
\hline Progress Test & 0.080 & 112 & 0,061 \\
\hline IPK & 0.082 & 112 & 0,077 \\
\hline
\end{tabular}

1. Hasil Analisis Univariat

a. Distribusi Rata-Rata Nilai Progress Test Pendidikan Profesi Dan Nilai IPK Lulusan Dokter Gigi

Distribusi rata-rata nilai progress test pendidikan profesi dan nilai IPK lulusan dokter gigi dapat dilihat pada Tabel 4 berikut:

Tabel 2. Distribusi Rata-Rata Nilai Progress Test Pendidikan Profesi Dan Nilai IPK Lulusan Dokter Gigi

\begin{tabular}{ccccc}
\hline & Mean & Maksimum & Minimum & St.Deviasi \\
\hline $\begin{array}{c}\text { Progress } \\
\text { Test }\end{array}$ & 45,42 & 66,00 & 29,99 & 7,30 \\
\hline IPK & 3,40 & 3,65 & 3,05 & 0,11 \\
\hline
\end{tabular}

Tabel 2 menunjukkan bahwa rata-rata nilai progress test yaitu 42,42 dan rata-rata nilai IPK yaitu 3,40. rata-rata nilai progress test yang teringgi yaitu 66,00 dan yang terendah 29,99, sedangkan rata-rata nilai IPK yang tertinggi yaitu 3,65 dan yang terendah yaitu 3,05 .

b. Distribusi Rata-Rata Nilai Progress Test Berdasarkan Tahun Angkatan

Distribusi rata-rata nilai progress test berdasarkan tahun angkatan dapat dilihat pada Tabel 3 berikut:
Tabel 3. Distribusi Rata-Rata Nilai Progress Test Berdasarkan Angkatan

\begin{tabular}{ccccc}
\hline Angkatan & Mean & Maksimum & Minimum & St.Deviasi \\
\hline 2006 & 42,46 & 56,11 & 30,55 & 6,47 \\
2007 & 46,25 & 65,55 & 29,99 & 7,37 \\
2008 & 46,55 & 66,00 & 37,63 & 7,51 \\
\hline
\end{tabular}

Tabel 3 menunjukkan bahwa rata-rata nilai progress test tertinggi yaitu pada angkatan 2008 dengan nilai rata-rata progress test sebesar 46,55, sedangkan nilai progress test yang tertinggi yaitu pada angkatan 2008 dengan nilai progress test sebesar 66,00 dan nilai progress test terendah yaitu pada angkatan 2007 dengan nilai progress test 29,99 .

Tabel 4. Distribusi Rata-Rata Nilai Progress Test Berdasarkan Jenis Kelamin

\begin{tabular}{lllll}
\hline $\begin{array}{l}\text { Jenis } \\
\text { Kelamin }\end{array}$ & Mean & Maksimum & Minimum & St.Deviasi \\
\hline Laki-Laki & 44,26 & 65,55 & 36,11 & 7,04 \\
Perempuan & 45,73 & 66,00 & 29,99 & 7,42 \\
\hline
\end{tabular}

c. Distribusi Rata-Rata Nilai Progress Test Berdasarkan Jenis Kelamin

Distribusi rata-rata nilai progress test berdasarkan jenis kelamin dapat dilihat pada Tabel 4 diatas.

Tabel 4 menunjukkan bahwa rata-rata nilai progress test tertinggi yaitu pada perempuan dengan nilai rata-rata progress test 45,73, sedangkan nilai progress test tertinggi dan terendah yaitu pada perempuan dengan nilai tertinggi 66,00 dan nilai terendah 29,99.

d. Distribusi Rata-Rata Nilai IPK Berdasarkan Tahun Angkatan 
Distribusi rata-rata nilai IPK berdasarkan tahun angkatan dapat dilihat pada Tabel 5 berikut:

Tabel 5. Distribusi Rata-Rata Nilai IPK Berdasarkan Tahun Angkatan

\begin{tabular}{ccccc}
\hline Angkatan & Mean & Maksimum & Minimum & St.Deviasi \\
\hline 2006 & 3,36 & 3,62 & 3,05 & 0,13 \\
2007 & 3,42 & 3,65 & 3,15 & 0,11 \\
2008 & 3,38 & 3,58 & 3,15 & 0,09 \\
\hline
\end{tabular}

Tabel 5 menunjukkan bahwa rata-rata nilai IPK tertinggi yaitu angkatan 2007 dengan nilai rata-rata IPK sebesar 3,42. Nilai IPK tertinggi yaitu pada angkatan 2007 dengan nilai IPK sebesar 3,65 dan nilai IPK terendah yaitu pada angkatan 2006 dengan nilai IPK sebesar 3,05.

e. Distribusi Rata-Rata Nilai IPK Berdasarkan Jenis Kelamin

Distribusi rata-rata nilai IPK berdasarkan jenis kelamin dapat dilihat pada Tabel 6 berikut:

Tabel 6. Distribusi Rata-Rata Nilai IPK Berdasarkan Jenis Kelamin

\begin{tabular}{lllll}
\hline $\begin{array}{l}\text { Jenis } \\
\text { Kelamin }\end{array}$ & Mean & Maksimum & Minimum & St.Deviasi \\
\hline Laki-Laki & 3,33 & 3,58 & 3,05 & 0,10 \\
Perempuan & 3,41 & 3,65 & 3,13 & 0,11 \\
\hline
\end{tabular}

Tabel 6 menunjukkan bahwa rata-rata nilai IPK tertinggi yaitu pada perempuan dengan nilai rata-rata IPK sebesar 3,41. Nilai IPK tertinggi yaitu pada perempuan dengan nilai IPK 3,65 dan nilai IPK terendah pada laki-laki dengan nilai IPK 3,05 .

3. Hasil Analisis Uji Pearson Analisa data hubungan progress test dengan
IPK menggunkan uji korelasi dengan metode Pearson karena distribusi data normal. Hasil analisa korelasi dengan metode Pearson dapat dilihat pada Tabel 7 berikut:

Tabel 7. Hasil analisis uji Pearson

\begin{tabular}{cll}
\hline & \multicolumn{2}{l}{ Nilai Progress Test } \\
\hline \multirow{4}{*}{ Nilai IPK } & $\mathrm{r}$ & 0,412 \\
& $\mathrm{P}$ & $<0,001$ \\
& $\mathrm{~N}$ & 112 \\
\hline
\end{tabular}

Tabel 7 menunjukkan bahwa hasil dari analisa uji Pearson tersebut adalah adanya hubungan antara nilai progress test pendidikan profesi dengan nilai IPK lulusan dokter gigi lebih dari 0,05. Nilai progress test pendidikan profesi dengan nilai

IPK lulusan dokter gigi memiliki korelasi yang sedang $(r=0,412)$

\section{PEMBAHASAN}

Hasil dari analisis univariat diperoleh hasil bahwa distribusi rata-rata nilai progress test pendidikan profesi berdasarkan tahun angkatan memiliki nilai rata-rata yang hampir sama yaitu nilai rata-rata progress test tahap profesi angkatan 2006 sebesar 42,46, angkatan 2007 sebesar 46,25 dan angkatan 2008 sebesar 46,55, hal tersebut menujukkan bahwa nilai rata-rata progress test pendidikan profesi berdasarkan angkatan masih belum memenuhi kriteria minimum untuk dikatakan lulus progress test pendidikan profesi. Mahasiswa dikatakan lulus apabila nilai progress test tahap profesi lebih dari sama dengan 60 dan dikatakan tidak lulus atau gagal apabila nilai progress test tahap profesi kurang dari $60^{4}$.

Distribusi rata-rata nilai progress test tahap profesi berdasarkan jenis kelamin menunjukkan 
Sri Utami, Indri Kurniasih, Arina Ismah Afiati | Hubungan Antara Nilai Progress Test Dengan Nilai Indeks Prestasi Kumulatif Lulusan Dokter Gigi Program Studi Pendidikan Profesi Dokter Gigi Universitas Muhammadiyah Yogyakarta

rata-rata nilai yang hampir sama, yaitu nilai rata-rata progress test pendidikan profesi pada laki-laki sebesar 44,26 dan rata-rata progress test pendidikan profesi pada perempuan sebesar 45,73 , hal tersebut menunjukkan bahwa nilai rata-rata progress test tahap profesi berdasarkan jenis kelamin juga masih belum memenuhi kriteria minimum untuk dapat lulus progress test pendidikan profesi.

Distribusi rata-rata nilai IPK lulusan dokter gigi berdasarkan tahun angkatan memiliki nilai rata-rata yang hampir sama pada setiap angkatan yaitu rata-rata nilai IPK pada angkatan 2006 sebesar 3,36, angkatan 2007 sebesar 3,42, dan angkatan 2008 sebesar 3,38. Rata-rata nilai IPK tersebut termasuk dalam kategori memuaskan ${ }^{7}$. Distribusi rata-rata nilai IPK berdasarkan jenis kelamin memiliki rata-rata yang hampir sama yaitu nilai rata-rata IPK pada laki-laki sebesar 3,33 dan nilai rata-rata pada perempuan sebesar 3,41, hal tersebut juga menunjukkan bahwa nilai rata-rata IPK berdasarkan dari jenis kelamin juga termasuk dalam kategori memuaskan.

Hasil dari analisa deskriptif nilai progress test dan nilai IPK didapatkan bahwa nilai progress test tertinggi dan terendah berdasarkan jenis kelamin yaitu perempuan memiliki nilai progress test tertinggi sebesar 66,00 dan terendah sebesar 29,99, sedangkan berdasarkan tahun angkatan diketahui bahwa nilai progress test tertinggi pada mahasiswa angkatan 2008 dengan nilai 66,00 dan nilai progress test terendah pada mahasiswa angkatan 2007 dengan nilai 29,99. Hasil analisa nilai IPK berdasarkan jenis kelamin yaitu jenis kelamin perempuan yang memiliki nilai IPK yang lebih tinggi dibandingkan dengan nilai IPK dari laki- laki yaitu sebesar 3,65, sedangkan analisa nilai IPK berdasarkan tahun angkatan yang memiliki rata-rata nilai IPK yang paling tinggi diantara angkatan lainnya yaitu pada angkatan 2007 dengan nilai IPK 3,65.

Perbedaan nilai progress test dan nilai IPK pendidikan profesi dipengaruhi oleh karakteristik jenis kelamin. Perempuan biasanya memiliki nilai dan prestasi yang lebih tinggi dibanding dengan laki-laki karena perempuan cenderung lebih tekun dan lebih kompetitif selain itu perempuan lebih rajin dalam mengerjakan tugas, belajar maupun berangkat untuk menempuh pendidikan, tetapi perempuan justru lebih cenderung terbawa perasaan dan kurang bisa menggunakan logika ${ }^{11}$, sehingga dapat dilihat pada penelitian ini bahwa rata-rata nilai IPK dan progress test lebih tinggi pada perempuan dibandingkan dengan laki-laki.

Hasil analisis data dan pengujian hipotesis diperoleh hasil bahwa terdapat hubungan yang signifikan antara nilai IPK tahap profesi dengan nilai progress test tahap profesi mahasiswa PPDG UMY dari angkatan 2006 sampai dengan angkatan 2008, yaitu dengan koefisien korelasi sebesar 0,417 . Nilai IPK tahap profesi dengan nilai progress test tahap profesi memiliki kekuatan hubungan yang sedang dan arah hubungan yang positif, sehingga semakin tinggi nilai progress test tahap profesi makan semakin tinggi pula nilai progress test tahap profesi, sehingga hipotesis pada penelitian ini diterima.

\section{KESIMPULAN}

Nilai progress test berhubungan dengan nilai IPK lulusan dokter gigi Program Pendidikan Profesi Dokter Gigi UMY, semakin besar nilai progress test, maka semakin besar pula nilai 
IPK lulusan dokter gigi UMY. Nilai progress test digunakan untuk menilai performance dan keterampilan dari mahasiswa serta kemampuan mahasiswa dalam mengambil keputusan, sehingga apabila nilai IPK mahasiswa tinggi maka keterampilan, performance dan kemampuan mahasiswa dalam mengambil keputusan juga tinggi.

\section{DAFTAR PUSTAKA}

1. Direktorat Jenderal Pendidikan Tinggi. (2011). Draft Naskah Akdemik Revisi Standar Pendidikan Dokter Gigi Indonesia.

2. Konsil Kedokteran Indonesia. (2006). Standar Kompetensi Pendidikan Dokter Gigi Indonesia. Jakarta.

3. Konsil Kedokteran Indonesia. (2012). Standar Pendidikan Profesi Dokter Indonesia. Jakarta.

4. Program Studi Pendidikan Dokter Gigi Universitas Muhammadiyah Yogyakarta (2011). Buku Panduan Kepaniteraan Klinik. Yogyakarta : Universitas Muhammadiyah Yogyakarta.

5. Program Studi Pendidikan Dokter Gigi Universitas Muhammadiyah Yogyakarta (2012). Buku Panduan Akademik Program Studi Pendidikan Dokter Gigi.Yogyakarta : Universitas Muhammadiyah Yogyakarta.
6. Daruyansi S., Wilandari W., dan Yasin H. (2013). Faktor - Faktor Yang Mempengaruhi Indeks Prestasi Mahasiswa FSM Universitas Diponegoro Semester Pertama Dengan Metode Regresi Logistik Biner.

7. Peraturan Menteri Riset, Teknologi, dan Pendidikan Tinggi Republik Indonesia Nomor 44 (2015). Standar Nasional Pendidikan Tinggi. Jakarta.

8. Boshuizen H.P.A., Vleuten C.P.M., Schmidt H.G., Bongaerts M.M. (1997). Measuring Knowledge and Clinical Reasoning Skills in a Problem Based Curriculum. Journal of Medical Education. Vol. 31 : Hal. 115121.

9. Neville A.J., Cunnington J.P.W., and Norman G.R. (2012). Development of Clinical Reasoning Exercises in a ProblemBased Curriculum. Journal of Advances in mEdical Education. Hal : 377-379.

10. Alwan I.A., Al-Moamary M., Al-Attas N., Al-Kushi A., Al-Banyan E., dkk. (2011). The Progress Test as a Diagnostic Tool for a New PBL Curriculum. Hal : 1-10.

11. Saptoto R. (2010). Hubungan Kecerdasan Emosi dengan Kemampuan Coping Adaptif. Jurnal Psikologi. Vol. 37. No.1: Hal. 13-22. 